\title{
Media Fun Thinkers Berbasis Soal Literasi untuk Siswa Kelas III Sekolah Dasar Pada Tema 1 Pertumbuhan dan Perkembangan Makhluk Hidup
}

\author{
Ni Luh Wayan Rata Dewi1*, Ni Ketut Suarni2, I Gusti Ayu Tri Agustiana ${ }^{3}$
}

1,2,3 Universitas Pendidikan Ganesha, Singaraja, Indonesia

\section{ART I CLE I N F O}

\section{Article history:}

Received May 15, 2021

Revised May 17, 2021

Accepted July 03, 2021

Available online July 25, 2021

Kata Kunci:

Media Fun Thinkers, Soal

Literasi

Keywords:

Fun Thinkers Media, Literacy Question



This is an open access article under the CC BY-SA license.

Copyright (C) 2021 by Author. Published by Universitas Pendidikan Ganesha.

\begin{abstract}
A B S T R A K
Rendahnya minat belajar siswa dalam pembelajaran dapat berdampak terhadap penurunan hasil belajar siswa. Pembelajaran memerlukan media yang menarik minat siswa untuk belajar. Tujuan penelitian ini adalah untuk mengembangkan dan menciptakan media fun thinkers berbasis soal literasi yang valid dan praktis pada topik pertumbuhan dan perkembangan makhluk hidup di kelas III sekolah dasar. Jenis penelitian ini adalah penelitian pengembangan dengan menggunakan model 4D. Subjek penelitian ini adalah 3 ahli media, 3 ahli materi soal, 2 praktisi, dan 10 siswa. Metode yang digunakan dalam pengumpulan data penelitian ini adalah metode nontes berupa kuesioner dalam bentuk rating scale dengan rentang 5-1. Data yang diperoleh kemudian dianalisis dengan menghitung indeks validitas penilaian ahli serta menghitung rata-rata respon praktisi dan siswa. Hasil analisis data validitas ahli media memperoleh skor terendah sebesar 0,83 dan skor tertinggi sebesar 1 sedangkan ahli materi soal memperoleh skor terendah sebesar 0,83 dan skor teringgi sebesar 1. Hal ini menunjukkan bahwa validitas media fun thinkers berbasis soal literasi sangat valid. Rata-rata skor penilaian respon praktisi sebesar 5. Rata-rata skor penilaian respon siswa sebesar 4,81. Dengan begitu, secara keseluruhan penilaian respon praktisi dan respon siswa terhadap media fun thinkers berbasis soal literasi berada pada rentang 4,01 $<\mathrm{x}<5,01$ dengan kualifikasi sangat baik. Berdasarkan hasil analisis tersebut, media fun thinkers berbasis soal literasi pada topik pertumbuhan dan perkembangan makhluk hidup di kelas III sekolah dasar dinyatakan valid dan layak digunakan dalam proses pembelajaran.
\end{abstract}

\section{A B S TRACT}

The low interest of students in learning can have an impact on decreasing student learning outcomes. Learning requires media that attracts students' interest in learning. The purpose of this research is to develop and create media for fun thinkers based on valid and practical literacy questions on the topic of growth and development of living things in grade III elementary school. This type of research is development research using 4D models. The subjects of this study were 3 media experts, 3 subject matter experts, 2 practitioners, and 10 students. The method used in collecting data in this study is a non-test method in the form of a questionnaire in the form of a rating scale with a range of 5-1. The data obtained were then analyzed by calculating the validity index of expert judgment and calculating the average response of practitioners and students. The results of the analysis of the validity of the media expert data obtained the lowest score of 0.83 and the highest score of 1 while the material expert obtained the lowest score of 0.83 and the highest score of 1 . This indicates that the validity of media fun thinkers based on literacy questions is very valid. The average score of the practitioner's response assessment is 5. The average score of the student response assessment is 4.81. That way, the overall assessment of practitioner responses and student responses to media fun thinkers based on literacy questions is in the range of $4.01<x<5.01$ with very good qualifications. Based on the results of the analysis, media fun thinkers based on literacy questions on the topic of growth and the development of living things in grade III elementary school are declared valid and suitable for use in the learning process.

\section{PENDAHULUAN}

Pembelajaran pada jenjang sekolah dasar saat ini menerapkan kurikulum 2013 dengan pembelajaran tematik. Pembelajaran tematik merupakan proses belajar mengajar yang terpadu menggunakan tema untuk saling mengaitkan beberapa mata pelajaran dengan pokok pikiran tertentu (Setiawan, 2020; Riani et al., 2019). Tercapainya hasil belajar secara optimal memerlukan minat belajar yang tinggi dari siswa. Menarik minat siswa untuk mengikuti proses pembelajaran memerlukan inovasi guru dalam merancang pembelajaran sehingga siswa memiliki minat dan motivasi selama proses pembelajaran (Chang et al., 2020; Philip, 2018). Proses belajar yang baik adalah proses belajar yang bisa 
memudahkan siswa dalam memahami materi pelajaran yang diajarkan (Aslianda et al., 2017; Budiarnawan et al., 2014; Rizqi \& Sumantri, 2019; Sugiartini et al., 2019). Kemampuan guru dalam mengajar sangat menentukan capaian hasil belajar siswa. Pembelajaran harus dirancang semenarik mungkin oleh guru dengan teknik yang baru, dengan kemasan yang bagus didukung media yang menarik perhatian siswa untuk belajar (Suprihatin, 2015; Maswin et al., 2020; Sabrina et al., 2017; Moslem et al., 2019). Guru perlu memperhatikan hal-hal yang menjadi bagian penting pembelajaran. Sesuai kurikulum 2013 terdapat 5 komponen penting dalam pembelajaran, yaitu materi, metode/model, strategi pembelajaran, media pembelajaran, serta penilaian (Kurniawati \& Mawardi, 2021). Berdasarkan hal tersebut, pembelajaran tematik memerlukan penggunaan media agar menarik minat siswa untuk mengalami dan aktif menemukan sendiri makna dari materi yang diajarkan.

Namun, pada kenyataannya penggunaan media dalam pembelajaran tematik masih jarang ditemukan. Hal ini mengakibatkan proses pembelajaran tematik di sekolah dasar memiliki kualitas yang masih rendah. Masalah dalam proses pembelajaran ini dapat berpengaruh terhadap hasil belajar siswa. Rendahnya hasil belajar siswa di Indonesia dibuktikan oleh hasil UNDP (United Nations Development Progame) tahun 2018 yang menunjukkan bahwa kualitas sumber daya manusia di Indonesia masih dalam kondisi terpuruk dengan menduduki peringkat 116 dari 189 negara di dunia (Utami \& Wardani, 2020). Selain itu, hasil studi pendahuluan yang telah dilaksanakan menggunakan kuesioner yang diajukan kepada wali kelas III tahun pelajaran 2020/2021 di Sekolah Dasar Gugus IV Kecamatan Tegallalang pada tanggal 02 sampai 04 Desember 2020 menunjukkan bahwa: 1) 83\% guru menyatakan sangat setuju bahwa siswa lebih bersemangat dalam belajar jika menggunakan media pembelajaran; 2) 83\% guru menyatakan sangat setuju bahwa perlu dikembangkannya media pembelajaran untuk mendukung pembelajaran tematik; 3) 67\% guru menyatakan sangat setuju bahwa melalui media fun thinkers siswa lebih mudah dalam memahami materi yang terdapat pada buku siswa; 4) 83\% guru menyatakan sangat setuju bahwa media fun thinkers dapat mengemas materi pelajaran dengan cara yang berbeda. Maka diperlukan suatu tindakan untuk menanggulangi semakin rendahnya kualitas pembelajaran di Indonesia khususnya pada pembelajaran tematik.

Upaya yang dapat dilakukan untuk mengatasi permasalahan tersebut adalah mengembangkan suatu media pembelajaran menyenangkan yang dapat membelajarkan materi dengan konkret serta dapat memberikan literasi kepada siswa dalam pembelajaran. Teori Jean Piaget menyatakan bahwa anak usia 712 tahun berada pada tahap operasi konkret yang mampu menggunakan operasi dan logikanya untuk objek yang nyata (Anditiasari \& Dewi 2021). Maka, pembelajaran siswa SD dapat ditunjang dengan media pembelajaran agar pembelajaran menjadi menarik, dan lebih nyata khususnya pada tema pertumbuhan dan perkembangan makhluk hidup di kelas III sekolah dasar (Agostinho, 2011). Media pembelajaran adalah alat atau perantara yang dapat digunakan untuk memudahkan proses pembelajaran, dalam rangka mengefektifkan komunikasi antara guru dan siswa (Efanudin \& Wibawa, 2017; Yunita \& Wijayanti 2017; Yuanta 2019; Wahyuningtyas \& Sulasmono 2020). Pengembangan media yang dapat meningkatkan kemampuan literasi siswa serta dapat meningkatkan motivasi siswa dalam belajar adalah berupa media fun thinkers berbasis soal literasi. Media fun thinkers adalah seperangkat buku yang termasuk media belajar permaianan (game) dikemas untuk menciptakan kegiatan pembelajaran agar lebih menyenangkan (Wijaya et al., 2021). Media fun thinkers dapat meningkatkan minat belajar siswa serta kemampuan berpikir kritis siswa khususnya dalam tematik yang dapat mengembangkan kemampuan berpikir kritis (Nst, 2020; Megawati, 2021). Soal literasi yang menjadi dasar dalam penyusunan media fun thinkers yang dikembangkan dapat meningkatkan kemampuan siswa untuk memahami, mengkomunikasikan, menerapkan, serta memecahkan masalah terkait dengan materi yang dibelajarkan (Fa'idah et al., 2019; Betari et al., 2020; Kusumastuti et al., 2019; Sommer et al., 2021). Melalui pengembangan media fun thinkers berbasis soal literasi dapat meningkatkan minat belajar siswa serta kemampuan berpikir kritis siswa dalam memahami, mengkomunikasikan, menerapkan, serta memecahkan masalah terkait dengan materi yang dibelajarkan. Media fun thinkers berbasis soal literasi pada topik pertumbuhan dan perkembangan makhluk hidup dibuat agar siswa dapat belajar sambil bermain karena siswa diajak untuk menganalisis suatu gambar, menjawab pertanyaan dengan mengamati gambar, dan menjodohkan sesuai isi gambar yang diberikan. Media fun thinkers dapat membangkitkan imajinasi siswa, mengatasi rasa bosan siswa saat mengikuti pembelajaran, dan penggunaan media ini dirasa sangat praktis (Maloy et al., 2019). Beberapa penelitian yang sudah dilakukan berkaitan dengan Media fun thinkers antara lain penelitian ini mengembangkan media fun thinkers berbasis soal literasi yang layak untuk digunakan (Riani et al., 2019). Penelitian yang menyatakan bahwa media fun thinkers pada pembelajaran IPA SD dapat meningkatkan kemampuan berpikir kreatif (Agustiana et al., 2020). Rancangan media media fun thinkers berbasis soal literasi dibuat semenarik mungkin agar dapat menumbuhkan minat belajar siswa yang didesain sesuai karakter anak SD. Keunggulan produk media Fun Thinkers Book terletak pada sifatnya yang mudah dibawa kemanapun, dengan tampilan yang menarik dan disertai dengan gambar 
kartun mengenai pertumbuhan dan perkembangan makhluk hidup. Perbedaan media fun thinkers yang dibuat dengan penelitian yang sudah pernah dilakukan sebelumnya adalah terletak pada soal literasi yang menjadi dasar dalam pembuatanya. Soal literasi dapat mempermudah siswa dalam memahami, mengkomunikasikan, menerapkan, serta memecahkan masalah terkait dengan materi yang dibelajarkan. Tujuan penelitian ini adalah untuk mengembangkan dan menciptakan media fun thinkers berbasis soal literasi yang valid dan praktis pada topik pertumbuhan dan perkembangan makhluk hidup di kelas III sekolah dasar

\section{METODE}

Penelitian ini merupakan penelitian pengembangan media pembelajaran yang dibuat dalam media fun thinkers. Penelitian pengembangan memiliki tujuan untuk fokus menghasilkan dan mengembangkan produk yang layak dan efektif digunakan dalam pembelajaran sehingga permasalahan pembelajaran dapat diselesaikan dengan produk yang dikembangakan (Tegeh \& Kirna, 2013). Penelitian ini menggunakan model 4D yang memiliki empat tahap yaitu: (1) pendefinisian (define), (2) perancangan (design), (3) pengembangan (development), dan (4) penyebaran (disseminate) (Diani, 2015). Pemilihan model pengembangan ini didasari atas pertimbangan bahwa desain pengembangan model 4D ini penyajian modelnya dilakukan secara sederhana (Tegeh et al., 2019). Subjek penelitian ini adalah 3 orang ahli media, 3 orang ahli materi soal, 2 orang praktisi, dan 10 orang siswa. Pemilihan subjek uji coba untuk ahli dan praktisi didasarkan atas kompetensi dan keahlian sesuai bidangnya masing-masing dengan kualifikasi keahlian minimal pada tingkat S1 dan pemilihan siswa disesuaikan dengan jenjang yang menjadi sasaran pembuatan media. Ahli media terdiri dari 3 orang dosen yang berkompeten dalam bidang media atau desain, ahli materi dan soal terdiri dari 3 orang dosen yang ahli dalam bidang materi dan instrumen tematik, praktisi terdiri dari 2 orang guru yang sudah memiliki pengalaman mengajar di Sekolah Dasar, dan 10 orang siswa yang sedang menempuh jenjang pendidikan di kelas III Sekolah Dasar.

Metode pengumpulan data yang digunakan dalam penelitian ini adalah metode non tes berupa kuesioner (angket). Metode pengumpulan data menggunakan kuesioner dilaksanakan dengan memberikan daftar pernyataan atau pertanyaan kepada responden (Agung, 2014). Kuesioner dalam penelitian ini adalah berbentuk skala bertingkat atau rating scale. Skala bertingkat atau rating scale adalah suatu alat pengumpul data dengan ukuran subjektif yang dibuat berskala atau bertingkat, Werther, et al., (dalam Ilhami \& Rimantho, 2017). Skala penilaian dalam penelitian pengembangan ini menggunakan rentang 5-1 untuk mengumpulkan data validitas media oleh para ahli. Instrumen dalam penelitian ini hendaknya memenuhi syarat uji validitas dan reliabilitas agar mencerminkan instrumen yang baik. Tahap yang dilalui untuk mengetahui validitas instrumen adalah sebagai berikut, yakni: 1) Membuat kisi-kisi instrumen dalam bentuk tabel, 2) mengkonsultasikan kisi-kisi dengan dosen pembimbing, 3) menyusun instrumen. Kisi-kisi intrumen validasi media fun thinkers berbasis soal literasi dasajikan pada Tabel 1, 2, 3, dan 4.

Tabel 1. Kisi-Kisi Instrumen Ahli Media

\begin{tabular}{|c|c|c|c|c|}
\hline No & Aspek & Indikator & No. Butir & Jumlah Butir \\
\hline \multirow[t]{4}{*}{1} & \multirow[t]{4}{*}{ Desain media } & Kualitas gambar yang ditampilkan & $1,2,3$ & 3 \\
\hline & & Kualitas teks yang ditampilkan & $4,5,6$ & 3 \\
\hline & & Tampilan media & $\begin{array}{c}7,8,9,10 \\
11\end{array}$ & 5 \\
\hline & & \multirow{2}{*}{$\begin{array}{l}\text { Tata letak } \\
\text { Kualitas penggunaan bahasa }\end{array}$} & $12,13,14$ & 3 \\
\hline 2 & Penggunaan bahasa & & $\begin{array}{c}15,16,17 \\
18\end{array}$ & 4 \\
\hline \multirow[t]{2}{*}{3} & $\begin{array}{l}\text { Kemudahan } \\
\text { penggunaan media }\end{array}$ & Kemudahan penggunaan media & 19,20 & 2 \\
\hline & & Jumlah Butir & & 20 \\
\hline
\end{tabular}

Tabel 2. Kisi-Kisi Instrumen Ahli Materi Soal

\begin{tabular}{cclcc}
\hline No & \multicolumn{1}{c}{ Aspek } & \multicolumn{1}{c}{ Indikator } & No. Butir & Jumlah Butir \\
\hline 1 & Penggunaan Bahasa & Kualitas penggunaan bahasa & $1,2,3$ & 3 \\
& \multirow{2}{*}{ Isi Soal } & $\begin{array}{l}\text { Kualitas susunan kalimat } \\
\text { Relevansi materi soal terhadap } \\
\text { kompetensi dasar }\end{array}$ & $4,5,6$ & 3 \\
& & $7,8,9$ & 3
\end{tabular}






Tabel 3. Kisi-Kisi Instrumen Respon Praktisi

\begin{tabular}{cllcc}
\hline No & \multicolumn{1}{c}{ Aspek } & \multicolumn{1}{c}{ Indikator } & No. Butir & Jumlah Butir \\
\hline 1 & Penggunaan bahasa & Kualitas penggunaan bahasa & $1,2,3$ & 3 \\
& & Kualitas penyusunan kalimat & 4,5 & 2 \\
2 & Isi soal & Relevansi materi soal & $6,7,8$ & 3 \\
3 & Desain media & Kualitas gambar yang ditampilkan & 9,10 & 2 \\
& & Kualitas teks yang ditampilkan & 11,12 & 2 \\
& & Tampilan media & $13,14,15$ & 3 \\
\multirow{2}{*}{4} & Penyajian soal & Tata letak & 16,17 & 2 \\
5 & Kemudahan penggunaan & Tampilan soal & 18 & 1 \\
& media & Kemudahan penggunaan media & 19,20 & 2 \\
\hline & & Jumlah butir & & $\mathbf{2 0}$ \\
\hline & & & (Mapicayanti et al., 2018)
\end{tabular}

Tabel 4. Kisi-Kisi Instrumen Respon Siswa

\begin{tabular}{|c|c|c|c|c|}
\hline No & Aspek & Indikator & $\begin{array}{c}\text { No. } \\
\text { Butir }\end{array}$ & $\begin{array}{c}\text { Jumlah } \\
\text { Butir }\end{array}$ \\
\hline \multirow{4}{*}{1} & \multirow{4}{*}{$\begin{array}{l}\text { Tampilan } \\
\text { media }\end{array}$} & Tampilan media fun thinkers menarik dan bagus. & 1 & 1 \\
\hline & & \multirow{3}{*}{$\begin{array}{l}\text { Huruf pada media fun thinkers dapat dibaca dengan jelas. } \\
\text { Gambar pada media fun thinkers dapat dibaca dengan } \\
\text { jelas. } \\
\text { Petunjuk pada setiap latihan dapat dipahami dengan baik. }\end{array}$} & 2 & 1 \\
\hline & & & 3 & 1 \\
\hline & & & 4 & 1 \\
\hline 2 & $\begin{array}{l}\text { Penggunaan } \\
\text { bahasa }\end{array}$ & Bahasa yang digunakan mudah dipahami. & 5 & 1 \\
\hline \multirow[t]{2}{*}{3} & \multirow{2}{*}{$\begin{array}{l}\text { Kemudahan } \\
\text { penggunaan }\end{array}$} & \multirow{2}{*}{$\begin{array}{l}\text { Media fun thinkers mudah digunakan. } \\
\text { Media fun thinkers dapat membantu dalam memahami } \\
\text { materi. }\end{array}$} & 6 & 1 \\
\hline & & & 7 & 1 \\
\hline \multirow[t]{4}{*}{4} & \multirow[t]{4}{*}{ Isi soal } & \multirow{3}{*}{$\begin{array}{l}\text { Materi soal pada media fun thinkers mudah dipahami. } \\
\text { Materi soal dapat menimbulkan rasa ingin mencoba terus } \\
\text { menerus. } \\
\text { Soal yang disajikan dalam media fun thinkers dapat } \\
\text { dijawab dengan baik. }\end{array}$} & 8 & 1 \\
\hline & & & 9 & 1 \\
\hline & & & 10 & 1 \\
\hline & & Jumlah Butir & & 10 \\
\hline
\end{tabular}

(Mapicayanti et al., 2018)

Metode analisis data yang digunakan dalam penelitian ini adalah metode analisis deskriptif kualitatif dan analisis deskriptif kuantitatif. Metode analisis deskriptif kualitatif digunakan untuk mengolah data yang bersumber dari komentar, tanggapan, kritik, dan saran berdasarkan hasil penilaian subjek penelitian terhadap media yang telah dikembangkan. Metode analisis deskriptif kuantitatif digunakan untuk menganalisis data berupa angka-angka yang diperoleh dari hasil uji produk. . Analisis deskriptif kuantitatif digunakan dengan tujuan untuk mengetahui indeks validitas skor ahli dan rata-rata skor yang telah diperoleh dari lembar penilaian respon praktisi dan respon siswa. Data yang diperoleh dari hasil uji produk selanjutnya dianalisis untuk mengetahui validitas produk yang dikembangkan. Analisis data dilakukan dengan menghitung indeks validitas penilaian oleh ahli materi dan ahli media serta menghitung rata-rata dari total skor yang diperoleh masing-masing aspek pada lembar penilaian respon praktisi dan respon siswa. Data indeks validitas tersebut kemudian dikonversikan pada pedoman 
konversi indeks validitas dan data berupa rata-rata dikonversikan pada pedoman konversi skala lima untuk mengetahui kategori validitas produk yang dikembangkan.

\section{HASIL DAN PEMBAHASAN}

Hasil

Penelitian yang dilakukan merupakan penelitian pengembangan dengan tujuan untuk menghasilkan suatu produk berupa media fun thinkers berbasis soal literasi untuk siswa sekolah dasar kelas III pada tema 1 pertumbuhan dan perkembangan makhluk hidup. Media fun thinkers berbasis soal literasi diujicobakan kepada 3 orang ahli materi soal dan 3 orang ahli media, serta penilaian terhadap media oleh 2 orang respon praktisi dan 10 orang respon siswa untuk membuktikan kelayakan produk dari segi validitasnya. Penelitian pengembangan ini dilakukan dengan menggunakan model pengembangan $4 \mathrm{D}$ yang terdiri dari tahap pendefinisian, tahap perancangan, tahap pengembangan, dan tahap penyebaran. Adapun penjabaran dari masing-masing tahapan adalah sebagai berikut.

\section{Tahap Pendefinisian}

Pada tahap pendefinisian dilakukan beberapa hal diantaranya, analisis kebutuhan, analisis kurikulum, analisis karakteristik siswa, dan analisis media. Dalam melakukan analisis kebutuhan diperoleh bahwa 83\% guru menyatakan sangat setuju bahwa siswa lebih bersemangat dalam belajar jika menggunakan media pembelajaran, $83 \%$ guru menyatakan sangat setuju bahwa perlu dikembangkannya media pembelajaran untuk mendukung pembelajaran tematik, 67\% guru menyatakan sangat setuju bahwa melalui media fun thinker siswa lebih mudah dalam memahami materi yang terdapat pada buku siswa, dan $83 \%$ guru menyatakan sangat setuju bahwa media fun thinkers dapat mengemas materi pelajaran dengan cara yang berbeda. Analisis karakteristik siswa menunjukkan bahwa anak pada usia SD berada pada tahap operasional konkret, dimana pada saat belajar anak memerlukan benda-benda yang nyata/konkret. Analisis media dilakukan guna mengetahui kriteria media dan dapat dijadikan pedoman dalam mengembangkan media fun thinkers berbasis soal literasi ini, dimana dalam mengembangkan media ini terdapat kriteria yang meliputi aspek desain media, aspek penggunaan bahasa, dan aspek kemudahan penggunaan media. Analisis kurikulum dilakukan dengan menganalisis kompetensi inti, kompetensi dasar, dan indikator pencapaian kompetensi yang terdapat pada buku guru dan buku siswa dengan muatan pelajaran seperti PPKn, Bahasa Indonesia, dan Matematika yang terdapat pada tema 1 pertumbuhan dan perkembangan makhluk hidup. Hasil analisis kurikulum yang menghasilkan Kompetensi Dasar dan Indikator pada masing-masing muatan pelajaran tema 1 pertumbuhan dan perkembangan makhluk hidup ditunjukan pada tabel 5.

Tabel 5. Hasil analisis kurikulum

\begin{tabular}{|c|c|c|c|c|c|}
\hline No. & $\begin{array}{c}\text { Muatan } \\
\text { Pelajaran }\end{array}$ & & Kompetensi Dasar & & Indikator \\
\hline 1 & $\begin{array}{l}\text { Bahasa } \\
\text { Indonesia }\end{array}$ & 3.4 & $\begin{array}{l}\text { Mencermati kosakata dalam teks } \\
\text { tentang konsep ciri-ciri, } \\
\text { kebutuhan (makanan dan tempat } \\
\text { hidup), pertumbuhan, dan } \\
\text { perkembangan makhluk hidup } \\
\text { yang ada di lingkungan setempat } \\
\text { yang disajikan dalam bentuk } \\
\text { lisan, tulis, visual, dan/atau } \\
\text { eksplorasi lingkungan. }\end{array}$ & $\begin{array}{l}3.4 .1 \\
3.4 .2\end{array}$ & $\begin{array}{l}\text { Menjelaskan ciri-ciri makhluk } \\
\text { hidup berdasarkan gambar. } \\
\text { Mengidentifikasi ciri- ciri } \\
\text { makhluk hidup berdasarkan } \\
\text { gambar. }\end{array}$ \\
\hline 2 & Matematika & 3.1 & $\begin{array}{l}\text { Menjelaskan sifat-sifat operasi } \\
\text { hitung pada bilangan cacah. }\end{array}$ & 3.1 .1 & $\begin{array}{l}\text { Memilih cara membilang } \\
\text { bilangan } 1.000 \text { sampai } 10.000 \\
\text { secara urut atau loncat. } \\
\text { Menghitung sifat-sifat operasi } \\
\text { hitung bilangan cacah. }\end{array}$ \\
\hline 3 & PPKn & 3.3 & $\begin{array}{l}\text { Menjelaskan makna keberagaman } \\
\text { karakteristik individu di } \\
\text { lingkungan sekitar. }\end{array}$ & 3.3 .1 & $\begin{array}{lr}\begin{array}{l}\text { Menerapkan } \\
\text { keberagaman }\end{array} & \text { karakteristik } \\
\text { individu di lingkungan sekitar. } & \\
\text { Menentukan } & \text { keberagaman } \\
\text { kebiasaan, kesukaan/hobi } & \\
\text { individu dalam kehidupan } & \text { sehari-hari di sekolah dan di }\end{array}$ \\
\hline
\end{tabular}




\begin{tabular}{llll}
\hline No. $\begin{array}{c}\text { Muatan } \\
\text { Pelajaran }\end{array}$ & Kompetensi Dasar & \multicolumn{1}{c}{ Indikator } \\
\hline & 3.4 & $\begin{array}{l}\text { Memahami makna bersatu dalam } \\
\text { keberagaman di lingkungan } \\
\text { sekitar. }\end{array}$ & $\begin{array}{l}\text { rumah. } \\
\text { Menjelaskan makna bersatu } \\
\end{array}$
\end{tabular}

\section{Tahap Perancangan}

Pada tahap perancangan dilakukan merancang media dengan membuat rancangan media fun thinkers menggunakan photoshop CS6, kemudian dicetak menggunakan kertas art paper 100 gsm untuk bagian isi dan kertas art paper 210 gsm untuk sampul. Media fun thinkers berbasis soal literasi yang dikembangkan terdiri dari sampul media, petunjuk penggunaan media, kompetensi dasar dan indikator, daftar isi, dan bagian isi. Adapun desain sampul media fun thinkers disajikan pada Gambar 1 dan bagian isi media fun thinkers berbasis soal literasi disajikan pada Gambar 2.

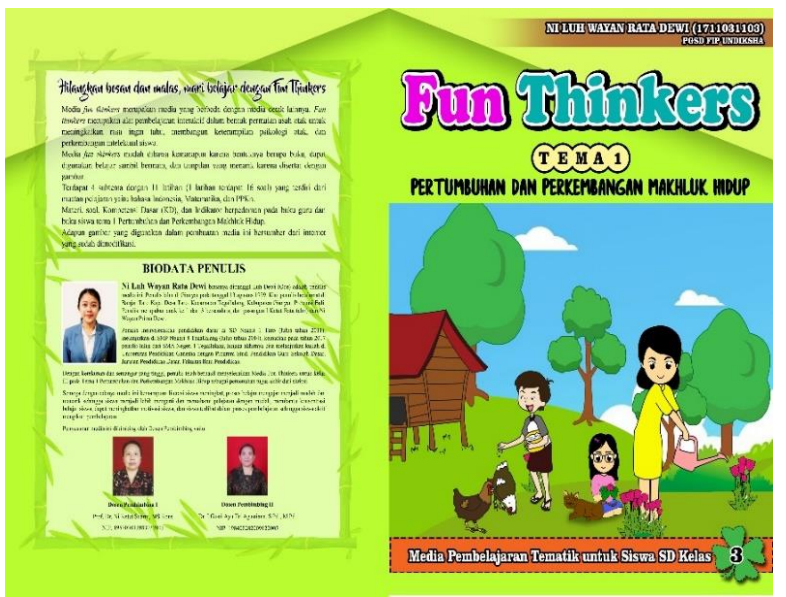

Gambar 1. Desain Sampul



Gambar 2. Isi Media Fun Thinkers

\section{Tahap Pengembangan}

Pada tahap pengembangan dilakukan proses uji oleh para ahli media, ahli materi soal, penilaian respon praktisi, dan respon siswa terhadap media yang dikembangkan. Pengujian oleh ahli media dan uj $\mathrm{i}$ ahli materi soal bertujuan untuk mendapatkan masukan dan saran terhadap media fun thinkers berbasis soal literasi yang dikembangkan. Uji ahli media melibatkan 3 orang dosen ahli dan uji ahli materi soal melibatkan 3 orang dosen ahli. Sedangkan untuk penilaian respon praktisi melibatkan 2 orang guru wali kelas III dan 10 orang siswa kelas III. Hasil validitas diperoleh bahwa validitas ahli media memperoleh skor terendah sebesar 0,83 dan skor tertinggi sebesar 1 . Skor validitas ahli media berada pada kategori sangat valid. Jadi, validitas ahli materi soal memperoleh skor terendah sebesar 0,83 dan skor tertinggi sebesar 1. Skor validitas ahli materi soal berada pada kategori sangat valid. Berdasarkan hasil penilaian respon praktisi diperoleh bahwa, media fun thinkers berbasis soal literasi dari segi respon praktisi memperoleh rata-rata skor dengan rentang 4,01<x $<5,01$ dari masing-masing butir penilaian. Rata-rata skor validitas media dari segi respon praktisi secara keseluruhan adalah 5. Apabila dikonversi menggunakan pedoman konversi skala lima, rata-rata skor validitas media dari segi respon praktisi secara keseluruhan berada pada rentangan 4,01 $<\mathrm{x}<5,01$ dengan kualifikasi sangat baik. Sedangkan hasil uji respon siswa menunjukkan bahwa, media fun thinkers berbasis soal literasi dari segi respon siswa memperoleh rata-rata skor dengan rentang 4,01 $<\mathrm{x}<5,01$ dari masing-masing butir penilaian dengan kualifikasi sangat baik. Rata-rata skor validitas media dari segi respon siswa secara keseluruhan adalah 4,81. Apabila dikonversi menggunakan pedoman konversi skala lima, rata-rata skor validitas media dari segi respon siswa secara keseluruhan berada pada rentangan 4,01<x<5,01 dengan kualifikasi sangat baik. Setelah pelaksanaan penilaian terhadap media fun thinkers berbasis soal literasi terdapat beberapa saran yang diberikan oleh ahli media dan ahli materi soal. Revisi dilakukan bertujuan untuk memperbaiki produk yang dihasilkan dengan harapan untuk mendapat media pembelajaran yang optimal. Hasil revisi media fun thinkers berbasis soal literasi pada tema 1 pertumbuhan dan perkembangan makhluk hidup disajikan pada Tabel 6. 
Tabel 6. Revisi Media Fun Thinkers Berbasis Soal Literasi pada Tema 1 Pertumbuhan dan Perkembangan Makhluk Hidup

\begin{tabular}{cl}
\hline No & \multicolumn{1}{c}{ Komentar } \\
\hline 1 & Pada cover tulis nama dosen pembimbing di bawah nama mahasiswa, semester ganjil atau \\
& genap. \\
2 & Petunjuk lengkapi dengan gambar pendukung. \\
3 & Lengkapi dengan titik-titik untuk kegiatan menulis \\
4 & Gunakan 1 jenis font untuk isi teks. \\
5 & $\begin{array}{l}\text { Penggunaan tata tulis (kata depan, awalan, kata berimbuhan), penggunaan kalimat efektif, dan } \\
\text { pemilihan gambar agar tidak menimbulkan pertanyaan bagi siswa. }\end{array}$ \\
\hline
\end{tabular}

\section{Tahap Penyebaran}

Penyebaran dilakukan dengan menyebarkan dan mempromosikan media fun thinkers berbasis soal literasi secara terbatas kepada 2 guru dan 10 siswa kelas III di SD Negeri 2 Taro serta 2 guru dan 5 siswa kelas III di SD Negeri 5 Taro. Dengan dilakukannya penyebaran media fun thinkers berbasis soal literasi ini diharapkan dapat membantu guru dalam menyampaikan materi pertumbuhan dan perkembangan makhluk hidup di sekolah dasar kelas III sehingga mendorong kemampuan literasi siswa, dapat memotivasi siswa, dan menciptakan suasana belajar yang menyenangkan.

\section{Pembahasan}

Tahap pendefinisian merupakan hal pertama yang mendasari pengembangan media fun thinkers berbasis soal literasi adalah hasil studi pendahuluan yang menunjukkan bahwa $83 \%$ guru menyatakan sangat setuju bahwa siswa lebih bersemangat dalam belajar jika menggunakan media pembelajaran, $83 \%$ guru menyatakan sangat setuju bahwa perlu dikembangkannya media pembelajaran untuk mendukung pembelajaran tematik, 67\% guru menyatakan sangat setuju bahwa melalui media fun thinker siswa lebih mudah dalam memahami materi yang terdapat pada buku siswa, dan $83 \%$ guru menyatakan sangat setuju bahwa media fun thinkers dapat mengemas materi pelajaran dengan cara yang berbeda. Untuk mengetahui muatan pelajaran yang akan dicantumkan dalam media yang dikembangkan terlebih dahulu dilakukan analisis kurikulum untuk menentukan kompetensi dasar dan indikato pada setiap muatan pelajaran. Selain analisis kurikulum, sebelum media dirancang juga dilakukan analisis karakteristik siswa agar media yang dikembangkan tepat untuk mencapai tujuan pembelajaran sesuai karakter siswa. Untuk menghasilkan media yang baik tentunya harus dilakukan analisis media agar dapat menentukan kriteria media yang baik, meliputi aspek desain media, aspek penggunaan bahasa, dan aspek kemudahan penggunaan media. Penggunaan media fun thinkers berbasis soal literasi dapat meningkatkan minat belajar siswa menarik dan memudahkan siswa memahami materi (Agustiana et al., 2020; Megawati, 2021; Peng \& Fu, 2021). Penerapan media fun thinkers berbasis soal literasi pada pembelajaran sesuai untuk meningkatkan hasil belajar siswa.

Tahap perancangan merupakan proses merancang media Fun Thinkers berbasis soal literasi yang kemudian dicetak menggunakan kertas art paper 100 gsm untuk bagian isi dan kertas art paper 210 gsm untuk sampul. Media fun thinkers berbasis soal literasi yang dikembangkan terdiri dari sampul media, petunjuk penggunaan media, kompetensi dasar dan indikator, daftar isi, dan bagian isi yang didesain sangat menarik sesuai karakter anak SD. Perbedaan media fun thinkers yang dibuat dengan penelitian yang sudah pernah dilakukan sebelumnya adalah terletak pada soal literasi yang menjadi dasar dalam pembuatanya. Soal literasi dapat mempermudah siswa dalam memahami, mengkomunikasikan, menerapkan, serta memecahkan masalah terkait dengan materi yang dibelajarkan (McQuillan, 1999; Safrizal et al., 2020). Penggunaan media fun thinkers berbasis soal literasi untuk siswa sekolah dasar efektif dan berbeda dengan media yang telah ada sebelumnya. Rancangan media media fun thinkers berbasis soal literasi dibuat semenarik mungkin agar dapat menumbuhkan minat belajar siswa. Keunggulan produk media Fun Thinkers Book terletak pada sifatnya yang mudah dibawa kemanapun, dengan tampilan yang menarik dan disertai dengan gambar kartun mengenai pertumbuhan dan perkembangan makhluk hidup (Hung et al., 2020; Riani et al., 2019; Anjarani et al., 2020).

Pengembangan media fun thinkers berbasis soal literasi yang telah disetujui oleh dosen pembimbing kemudian diimplementasikan secara terbatas kepada 3 orang ahli media, 3 orang ahli materi, 2 orang guru, dan 10 orang siswa untuk membuktikan validitas media fun thinkers berbasis soal literasi yang telah dibuat. Implementasi dilakukan dengan memberikan media fun thinkers berbasis soal literasi yang telah dibuat beserta instrumen kepada subjek penelitian untuk diberikan penilaian. Media media fun thinkers berbasis soal literasi yang dikembangkan dinyatakan valid pada kategori "sangat baik" berdasarkan konversi yang telah dilakukan. Selain itu, media fun thinkers berbasis soal literasi yang dikembangkan didasari hasil studi pendahuluan yang telah dilakukan yang sejalan dengan teori belajar 
kognitivistik, sesuai dengan karakteristik siswa SD, sesuai dengan aspek-aspek media yang baik, dan sesuai dengan karakteristik pembelajaran tematik di SD. Penggunaan media media fun thinkers berbasis soal literasi diyakini dapat menarik minat dan motivasi belajar siswa SD karena media ini menampilkan hal yang konkret sesuai dengan tahap perkembangan siswa SD yang berada pada tahap operasional konkret. Berdasarkan hal tersebut, diyakini bahwa penggunaan media fun thinkers berbasis soal literasi dapat meningkatkan minat dan hasil belajar siswa sekolah dasar. Hal ini sejalan dengan penelitian (Megawati, 2021; Agustiana et al., 2020; Riani et al., 2019) yang menyatakan media fun thinkers berbasis soal literasi layak dan efektif digunakan sebagai media pembelajaran siswa SD/MI sederajat serta menjadi media baru penunjang motivasi belajar siswa agar siswa aktif dalam proses pembelajaran.

Penyebaran media fun thinkers berbasis soal literasi ini diharapkan dapat membantu guru dalam menyampaikan materi pertumbuhan dan perkembangan makhluk hidup di sekolah dasar kelas III sehingga mendorong kemampuan literasi siswa, dapat memotivasi siswa, dan menciptakan suasana belajar yang menyenangkan. Pembelajaran tematik di SD akan sangat efektif apabila guru memfasilitasi siswa dengan media fun thinkers berbasis soal literasi. Hal ini karena media fun thinkers berbasis soal literasi sesuai dengan karakteristik pembelajaran tematik yang menampilkan suatu materi maupun konsep secara konkret sehingga siswa dapat; berpikir kritis untuk menemukan suatu konsep, menggunakan seluruh indera, aktif dengan difasilitasi oleh guru. Hal ini didukung oleh pendapat Fransisca \& Mintohari (2018); Megawati (2018) yang menyatakan bahwa dalam proses pembelajaran dibutuhkan suatu media yang dapat digunakan siswa sebagai sarana memahami materi secara nyata yang dipelajari serta mengaitkannya dalam kehidupan sehari-hari dengan menekankan proses untuk meningkatkan keatifan siswa dalam pembelajaran. Media fun thinkers berbasis soal literasi membuat pembelajaran lebih nyata karena siswa dapat melihat secara langsung materi dalam media sehingga memudahkan siswa memahami dengan baik materi yang diajarkan (Liew et al., 2017; Han, 2019). Hasil penelitian berupa media fun thinkers berbasis soal literasi memiliki implikasi sebagai media baru penunjang proses pembelajaran siswa yang berdampak terhadap peningkatan minat dan motivasi belajar siswa yang berpengaruh terhadap peningkatan hasil belajar siswa.

\section{SIMPULAN}

Media fun thinkers berbasis soal literasi pada topik pertumbuhan dan perkembangan makhluk hidup di kelas III sekolah dasar yang dihasilkan valid dan praktis digunakan dalam proses pembelajaran dengan kategori sangat baik. Hal ini dapat dilihat dari hasil penilaian ahli media, penilaian ahli materi soal, respon praktisi, dan repon siswa.

\section{DAFTAR PUSTAKA}

Agostinho, S. (2011). The use of a visual learning design representation to support the design process of teaching in higher education. Australasian Journal of Educational Technology, 27(6), 961-978. https://doi.org/10.14742/ajet.923.

Agung, A. A. G. (2014). Metode Penelitian Pendidikan. Aditya Media Publishing.

Anditiasari, N., \& Dewi, N. R. (2021). Analisis Teori Perkembangan Kognitif Piaget Pada Anak Usia 11 Tahun Di Brebes Piaget's Theory of Cognitive Development Analysis in 11 Year Olds in Brebes. Jurnal Matematika Dan Pendidikan Matematika, 6(1), 97-108. https://doi.org/10.31943/mathline.v6i1.177.

Anjarani, A. S., Mulyadiprana, A., \& Respati, R. (2020). Fun Thikers sebagai Media Pembelajaran untuk Siswa Sekolah Dasar: Kajian Hipotetik. PEDADIDAKTIKA: Jurnal Ilmiah Pendidikan Guru Sekolah Dasar, 7(4), 100-111. https: //ejournal.upi.edu/index.php/pedadidaktika/article/view/26466.

Betari, M. E., Yanthi, N., \& Rostika, D. (2020). Peningkatan Kemampuan Literasi Sains Siswa Melalui Penerapan Model Pembelajaran Berbasis Masalah pada Pembelajaran IPA di SD. Antologi UPI, 1(2), 1-17. https://training.unmuhkupang.ac.id/index.php/jpdf/article/view/159.

Budiarnawan, K. B., Antari, N. N. M., \& Rati, N. W. (2014). Hubungan Antara Konsep Diri Dan Pola Asuh Orang Tua Terhadap Hasil Belajar IPA Siswa Kelas V SD Di Desa Selat. Jurnal Mimbar PGSD Universitas Pendidikan Ganesha, 2(1). http://dx.doi.org/10.23887/jjpgsd.v2i1.2224.

Chang, T. Y., Hong, G., Paganelli, C., Phantumvanit, P., Chang, W. J., Shieh, Y. S., \& Hsu, M. L. (2020). Innovation of dental education during COVID-19 pandemic. Journal of Dental Sciences, 155. https://doi.org/10.1016/j.jds.2020.07.011.

Diani, R. (2015). Pengembangan Perangkat Pembelajaran Fisika Berbasis Pendidikan Karakter dengan Model Problem Based Instruction. Jurnal Ilmiah Pendidikan Fisika Al-Biruni, 4(2), 243-255. https: //doi.org/10.24042/jpifalbiruni.v4i2.96.

Efanudin, A. F., \& Wibawa, S. C. (2017). Pengembangan Media Pembelajaran Berbasis Video Animasi Pada 
Mata Pelajaran Pemrograman Dasar Untuk Siswa Kelas X Jurusan RPL Di SMK Krian 1 Sidoarjo. ItEdu, 2(02), 202-209. https://ejournal.unesa.ac.id/index.php/it-edu/article/view/22657/20779.

Fa'idah, R. N., H, S. K., \& Mahanal, S. (2019). Pengaruh Model Pembelajaran Inkuiri Terbimbing terhadap Literasi Sains Siswa Kelas V SD. Jurnal Pendidikan: Teori, Penelitian, Dan Pengembangan, 4(12), 1704-1709. http://dx.doi.org/10.17977/jptpp.v4i12.13096.

Fransisca, I., \& Mintohari. (2018). Pengembangan Media Pembelajaran Video Berbasis Sparkol Videoscribe Pada Pelajaran Ipa Dalam Materi Tata Surya Kelas Vi SD. Jurnal Penelitian Pendidikan Guru Sekolah Dasar, 6(11), 1916-1927. https://ejournal.unesa.ac.id/index.php/jurnal-penelitianpgsd/article/view/24661.

Han, Y. (2019). Exploring multimedia, mobile learning, and place-based learning in linguacultural education. Language Learning \& Technology, 23(3), 29-38. https://eric.ed.gov/?id=EJ1234122.

Hung, H. T., Yang, J. C., \& Tsai, Y. C. (2020). Student game design as a literacy practice: A 10-Year review. Educational Technology and Society, 23(1), 50-63. https://eric.ed.gov/?id=EJ1255781.

Ilhami, R. S., \& Rimantho, D. (2017). Penilaian Kinerja Karyawan dengan Metode AHP dan Rating Scale. Jurnal Optimasi Sistem Industri, 16(2), 150. https://doi.org/10.25077/josi.v16.n2.p150-157.2017.

Kurniawati, D., \& Mawardi. (2021). Pengembangan Instrumen Penilaian Sikap Gotong Royong dalam Pembelajaran Tematik di Sekolah Dasar. Edukatif: Jurnal Ilmu Pendidikan, 3(3), 640-648. https://doi.org/10.31004/edukatif.v3i3.387.

Kusumastuti, R. P., Rusilowati, A., \& Nugroho, S. E. (2019). Pengaruh Keterampilan Berpikir Krtis Terhadap Literasi Sains Siswa. UPEJ Unnes Physics Education Journal, 8(3), 254-261. https://doi.org/10.15294/upej.v8i3.35624.

Liew, T. W., Mat Zin, N. A., \& Sahari, N. (2017). Exploring the affective, motivational and cognitive effects of pedagogical agent enthusiasm in a multimedia learning environment. Human-Centric Computing and Information Sciences, 7(1). https://doi.org/10.1186/s13673-017-0089-2.

Maloy, J., Fries, L., Laski, F., \& Ramirez, G. (2019). Seductive details in the flipped classroom: The impact of interesting but educationally irrelevant information on student learning and motivation. CBE Life Sciences Education, 18(3). https://doi.org/10.1187/cbe.19-01-0004.

Mapicayanti, D., Jamaludin, J., \& Fathoni, A. (2018). Perancangan Media Pembelajaran Berbasis Video Tutorial Mendesain Jaringan Lokal/LAN Kelas X TKJ. EDUMATIC: Jurnal Pendidikan Informatika, 2(2), 59. https://doi.org/10.29408/edumatic.v2i2.913.

Maswin, Ilyas, M., \& Nurdin. (2020). Pengaruh Motivasi Berprestasi dan Pola Asuh Orang Tua Terhadap Hasil Belajar Matematika Siswa. Jurnal Penelitian Matematika Dan Pendidikan Matematika, 3(2), 24-30. https://doi.org/10.30605/2615-7667.482.

McQuillan, J. (1999). Seven myths about literacy in the United States. Practical Assessment, Research and Evaluation, 6(1), 1998-1999. https://files.eric.ed.gov/fulltext/ED509943.pdf.

Megawati. (2018). Pentingnya Pengakomodasian Pengalaman Belajar Pada Pembelajaran IPA. Jurnal Tunas Pendidikan, 1(1), 21-30. mmb.ac.id/index.php/pgsd/article/view/62.

Moslem, M. C., Komaro, M., \& Indonesia, U. P. (2019). Faktor-Faktor Yang Menyebabkan Rendahnya Motivasi Belajar Siswa Dalam Mata Pelajaran Aircraft Drawing Di Smk. Journal of Mechanical Engineering Education, 6(2), 258-265. https://doi.org/10.17509/jmee.v6i2.21803.

Nst, S. A. R. (2020). Pengembangan Media Pembelajaran Fun Thinkers Berbasis Scientific pada Tema 4 Berbagai Pekerjaan Subtema 1 Jenis-Jenis Pekerjaan Kelas IV di SDN 060912 Medan Denai T.A 2020/2021. Jurnal Keluarga Sehat Sejahtera, 18(1), 36-45. https://doi.org/10.24114/jkss.v18i1.25069.

Peng, R., \& Fu, R. (2021). The effect of Chinese EFL students' learning motivation on learning outcomes within a blended learning environment. Australasian Journal of Educational Technology, 37(6), 61-74. https://doi.org/10.14742/ajet.6235.

Philip, R. (2018). Finding creative processes in learning design patterns. Australasian Journal of Educational Technology, 34(2), 78-94. https://doi.org/10.14742/ajet.3787.

Riani, R. P., Huda, K., \& Fajriyah, K. (2019). Pengembangan Media Pembelajaran Tematik "Fun Thinkers Book" Tema Berbagai Pekerjaan. Jurnal Sinektik, 2(2), 173-184. https://doi.org/10.33061/js.v2i2.3330.

Rizqi, A. T., \& Sumantri, M. (2019). Hubungan Antara Motivasi Belajar Dan Pola Asuh Orang Tua Terhadap Hasil Belajar IPA. Jurnal Imiah Pendidikan Dan Pembelajaran, 3(2), 145-154. http://dx.doi.org/10.23887/jipp.v3i2.18071.

Sabrina, R., Fauzi, \& Yamin. (2017). Faktor-Faktor Penyebab Rendahnya Motivasi Belajar Siswa Dalam Proses Pembelajaran Matematika Di Kelas V Sd Negeri Garot Geuceu Aceh Besar. Jurnal Ilmiah $\begin{array}{llll}\text { Pendidikan Guru Sekolah } & \text { 2(4), }\end{array}$ 
http://www.jim.unsyiah.ac.id/pgsd/article/download/7736/3350.

Safrizal, Zaroha, L., \& Yulia, R. (2020). Kemampuan Literasi Sains Siswa Sekolah Dasar di Sekolah Adiwiyata (Studi Deksriptif di SD Adiwiyata X Kota Padang). Journal of Natural Science and Integration, 3(2), 215-223. https://doi.org/10.24014/jnsi.v3i2.9987.

Setiawan, A. R. (2020). Desain Pembelajaran Tematik untuk Membimbing Siswa Sekolah Dasar dalam Memperoleh Literasi Saintifik. Journal of Petrology, 369(1), 1689-1699. https://doi.org/10.1017/CB09781107415324.004.

Sommer, M., Kohnen, A., Ritzhaupt, A., \& Hampton, J. (2021). Investigation of the Validity Evidence of the Information Literacy Self-Efficacy Scale (ILSES) Among Undergraduate Students. Communications in Information Literacy, 15(1), 1-23. https://doi.org/10.15760/comminfolit.2021.15.1.1.

Sugiartini, N. K., Pudjawan, K., \& Renda, N. T. (2019). Hubungan Pola Asuh Orang Tua dan Rasa Percaya Diri Terhadap Hasil Belajar IPA Kelas V. Mimbar PGSD, 5(2), 171. https://doi.org/10.23887/ika.v17i2.19853.

Suprihatin, S. (2015). Upaya Guru Dalam Meningkatkan Motivasi Belajar Siswa. G-Couns: Jurnal Bimbingan Dan Konseling, 3(1), 73-82. https://doi.org/10.31316/g.couns.v3i1.89.

Tegeh, I. M., \& Kirna, I. M. (2013). Pengembangan Bahan Ajar Metode Penelitian Pendidikan dengan ADDIE Model. Jurnal Pendidikan, 11(1), 16. http://dx.doi.org/10.23887/ika.v11i1.1145.

Tegeh, I. M., Simamora, A. H., \& Dwipayana, K. (2019). Pengembangan Media Video Pembelajaran Dengan Model Pengembangan 4D Pada Mata Pelajaran Agama Hindu. Mimbar Ilmu, 24(2), 158. https://doi.org/10.23887/mi.v24i2.21262.

Wahyuningtyas, R., \& Sulasmono, B. S. (2020). Pentingnya Media dalam Pembelajaran Guna Meningkatkan Hasil Belajar di Sekolah Dasar. Edukatif: Jurnal Ilmu Pendidikan, 2(1), 23-27. https://doi.org/10.31004/edukatif.v2i1.77.

Wijaya, I. H., Ermiana, I., \& Khair, B. N. (2021). The Influence of Fun Thinkers Book Media Towards Science Concepts Understanding of 5Th Grade Student on Min 3 Central Lombok in 2020/2021 Academic Year. Progres Pendidikan, 2(2), 81-88. https://doi.org/10.29303/prospek.v2i2.128.

Yuanta, F. (2019). Pengembangan Media Video Pembelajaran Ilmu Pengetahuan Sosial pada Siswa Sekolah Dasar. Trapsila: Jurnal Pendidikan Dasar, 1(2), 91-100. http://dx.doi.org/10.30742/tpd.v1i02.816.

Yunita, D., \& Wijayanti, A. (2017). Pengaruh Media Video Pembelajaran Terhadap Hasil Belajar Ipa Ditinjau Dari Keaktifan Siswa. Sosiohumaniora: Jurnal Ilmiah Ilmu Sosial Dan Humaniora, 3(2), 153-160. https://doi.org/10.30738/sosio.v3i2.1614. 